\title{
Sensing Temperature in vitro and in Cells Using a BODIPY Molecular Probe
}

Meredith M. Ogle, ${ }^{\dagger}$ Ashleigh D. Smith McWilliams, ${ }^{\dagger}$ Matthew J. Ware ${ }^{\perp}$, Steven A. Curley ${ }^{\perp}$, , Stuart J. Corr $^{t, \perp, \|, ~}$, , Angel A. Marti ${ }^{*}, \dot{t}$,

${ }^{\dagger}$ Department of Chemistry, Department of Bioengineering and Department of Materials Science and Nanoengineering, Rice University, 6100 Main St MS60 Houston TX 77005. ${ }^{\perp}$ Department of Surgery, Baylor College of Medicine, Houston, TX, 77030. "Department of Surgery, CHRISTUS Trinity Mother Frances, 800 E. Dawson, Tyler, TX 75701. Department of Biomedical Engineering, University of Houston, Texas 77204. 'School of Medicine, Swansea University, Swansea, Wales, SA2 8PP, UK.

\section{Supplementary Information}

\section{Table of Contents}

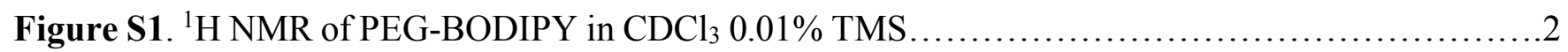

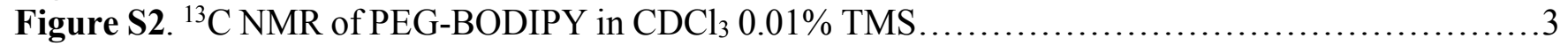

Figure S3. Lifetime of PEG-BODIPY in various $\mathrm{pH}$ or ionic strength...........................4

Figure S4. Lifetime of PEG-BODIPY at various temperatures in mixtures of water and glycerol........5

Figure S5. FACS raw data of HPNE cells stained with PEG-BODIPY ...........................6

Figure S6. FACS raw data of Panc-1 cells stained with PEG-BODIPY ............................

Figure S7. Colocalization of PEG-BODIPY in Panc-1 cells...................................

Figure S8. Colocalization of PEG-BODIPY in HPNE cells ......................................

Figure S9. Lifetime of PEG-BODIPY in different polarity solvents..............................9

Figure S10. PEG-BODIPY in DMEM growth media..........................................9

Figure S11. Lifetime of PEG-BODIPY at high concentrations................................ 11

Figure S12. Panc-1 FLIM studies.................................................... 12

Table S1. HPNE FACS data compiled .................................................6

Table S2. Panc-1 FACS data compiled...................................................... 7

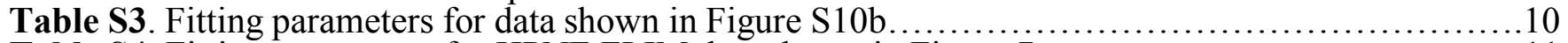

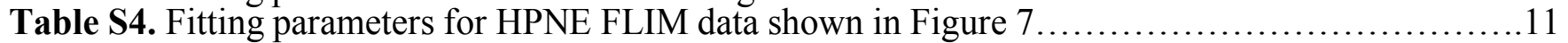

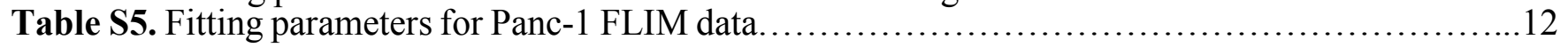


ํํㅇำ

$\rightarrow 00 \%$ लेलm

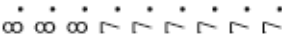

尔

N $\infty \infty N N m$ N

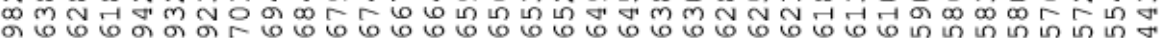

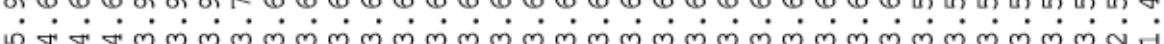

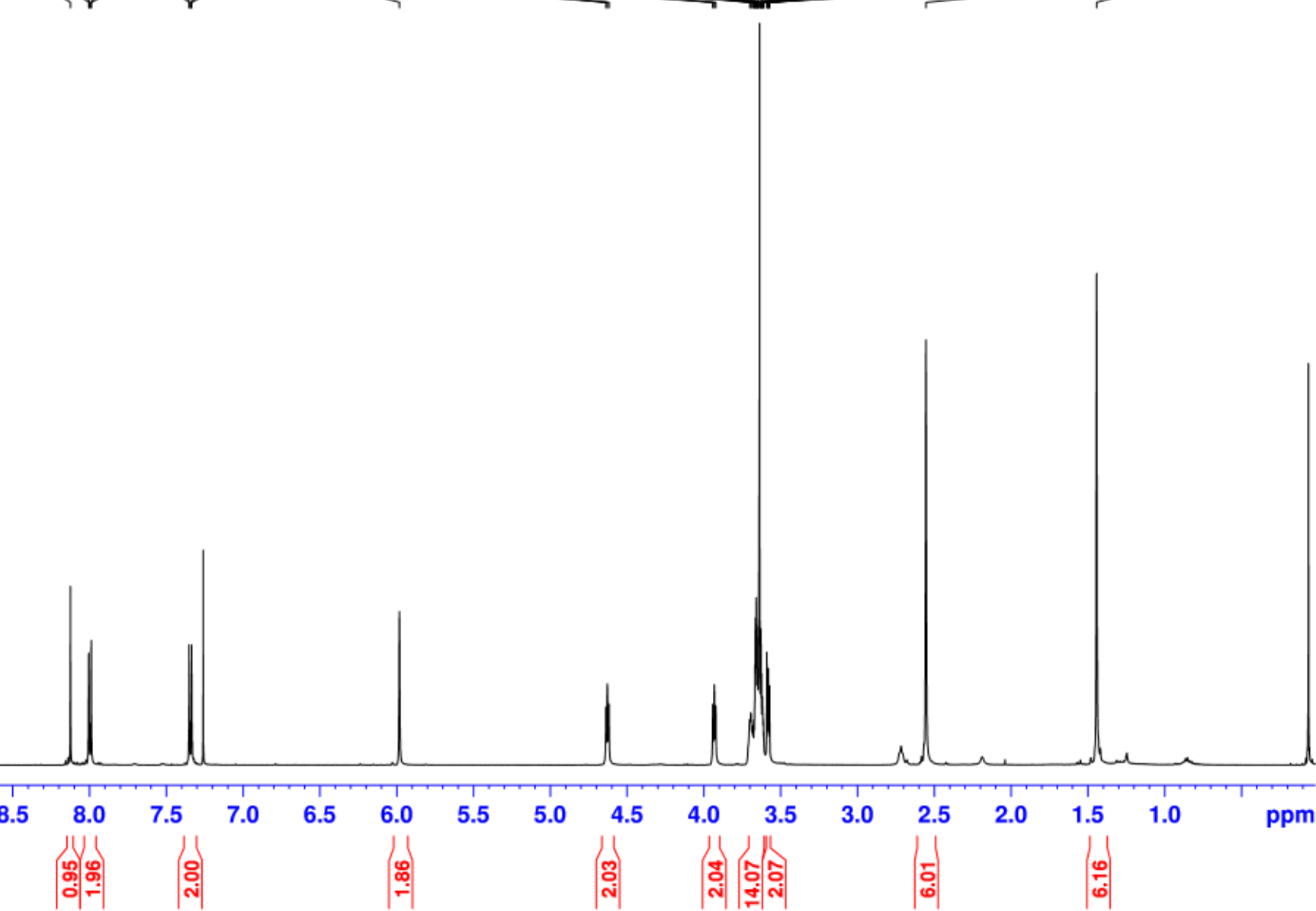

Figure S1. ${ }^{1} \mathrm{H}$ NMR of PEG-BODIPY in $\mathrm{CDCl}_{3} 0.01 \%$ TMS. 


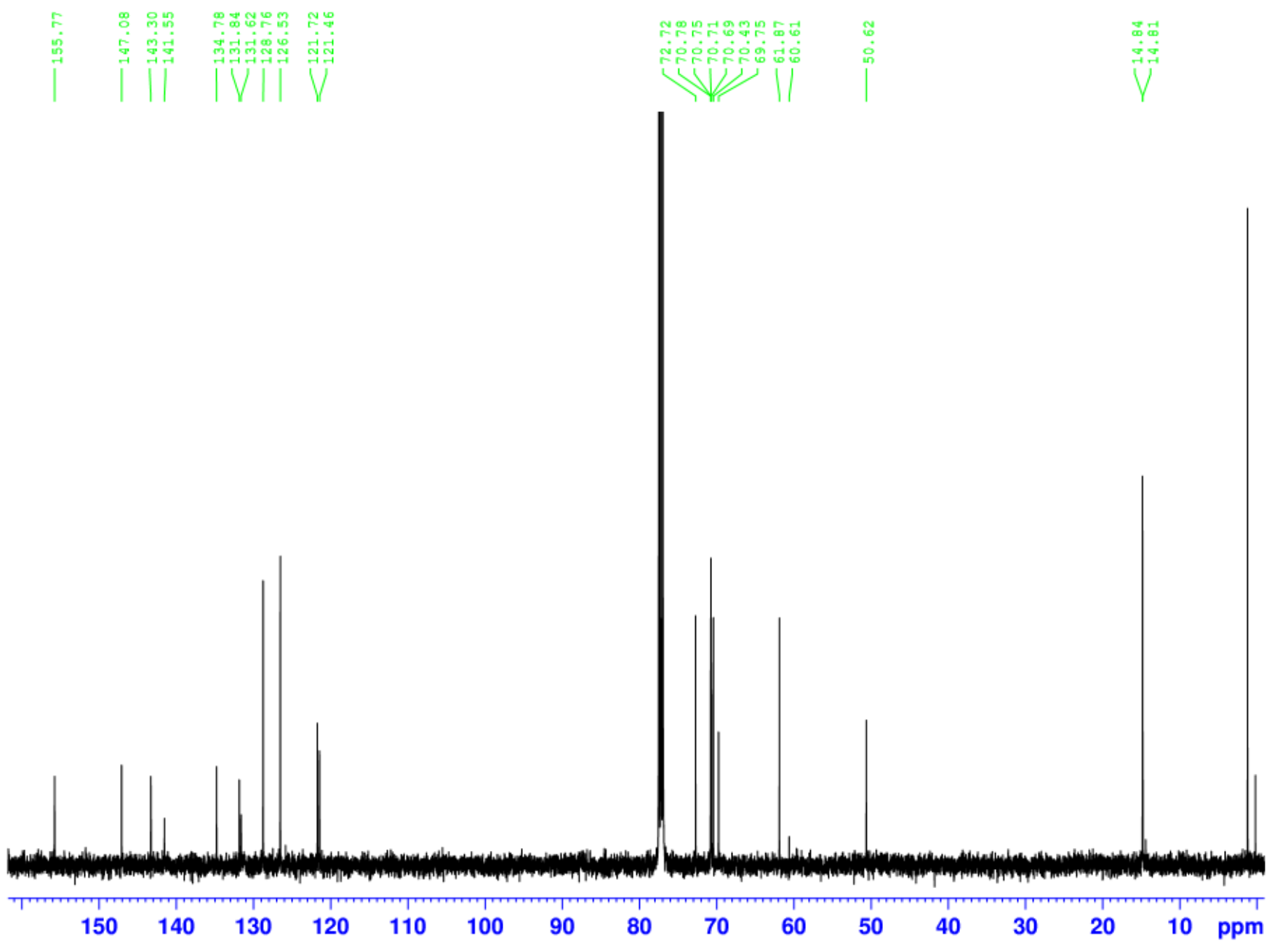

Figure S2. ${ }^{13} \mathrm{C}$ NMR of PEG-BODIPY in $\mathrm{CDCl}_{3} 0.01 \%$ TMS. 

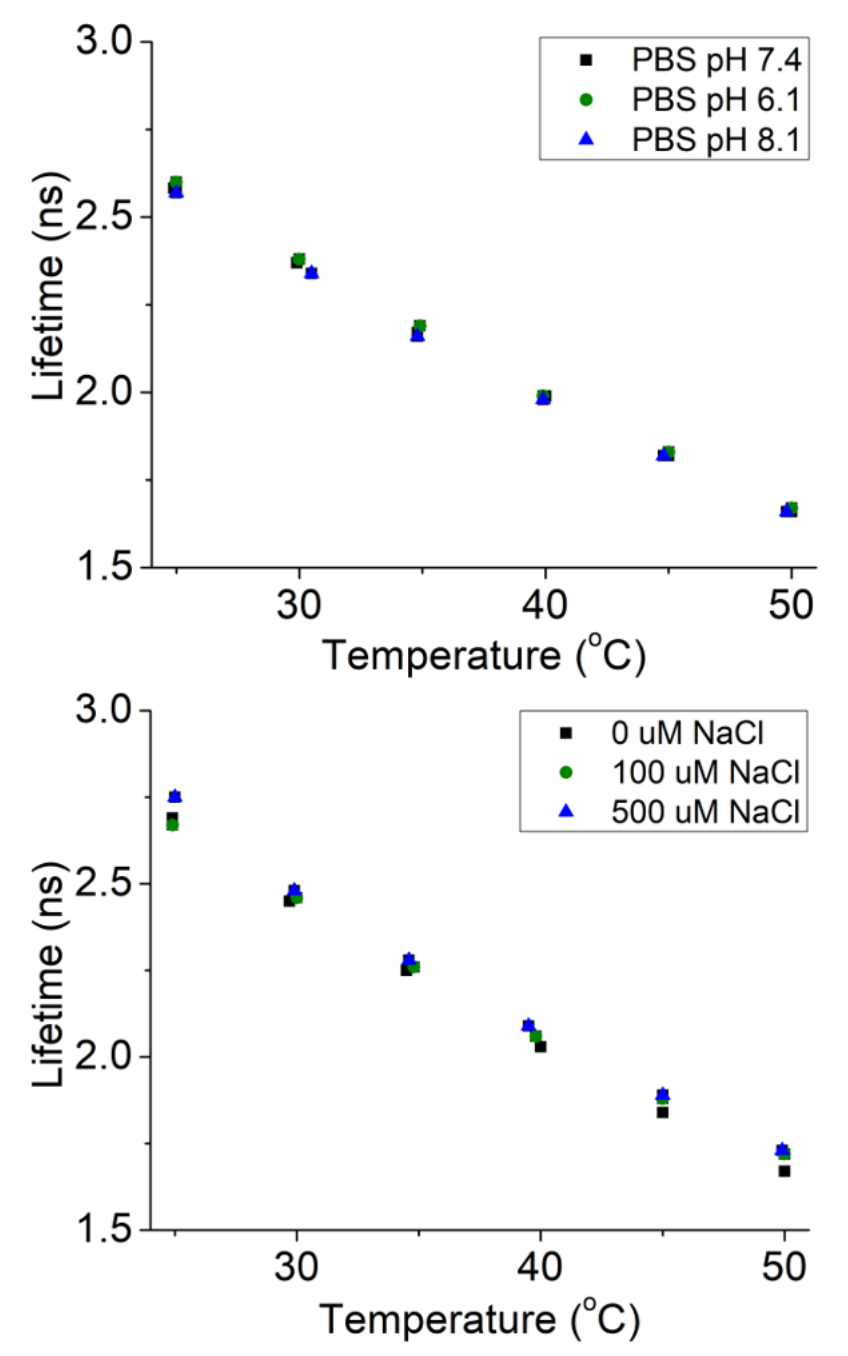

Figure S3. Lifetime of PEG-BODIPY in various $\mathrm{pH}$ or ionic strength buffers. Lifetime is not greatly affected by $\mathrm{pH}$ or ionic strength. 

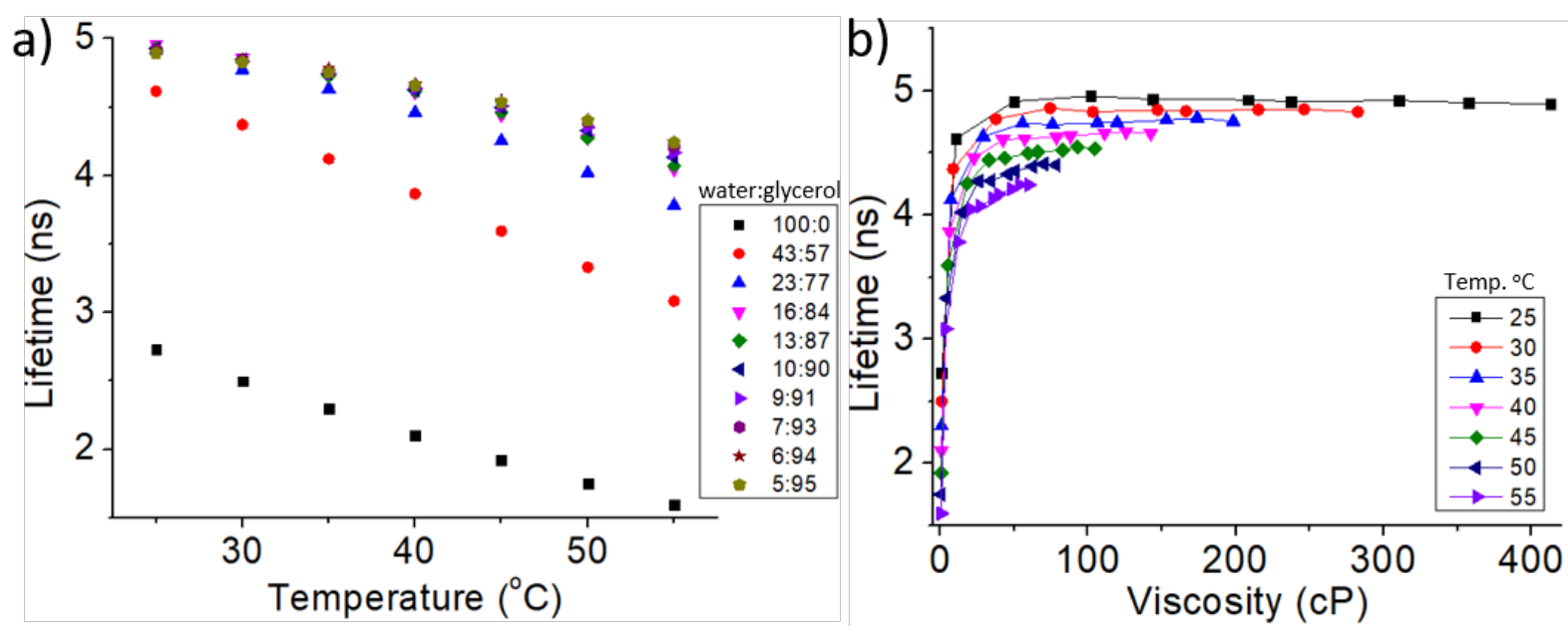

Figure S4. (a) Lifetime of PEG-BODIPY at various temperatures in several mixtures of water and glycerol $\left(\lambda_{\mathrm{ex}} 444 \mathrm{~nm}, \lambda_{\mathrm{em}} 515 \mathrm{~nm}\right)$. The response to temperature is very similar for water-glycerol mixtures with viscosities larger than $100 \mathrm{cP}$, with deviations for PEG-BODIPY in 100\% water, 43:57, and 23:77 water:glycerol mixtures. The temperature dependence PEG-BODIPY lifetime at low viscosities (such as 100\% water) can be explained by equation 4 . The temperature dependence of PEGBODIPY lifetime at high viscosities is similar for all viscosities studied with the exception of the 43:57 and 23:77 water:glycerol mixture curves, which are the lowest glycerol ratios used. This is due to the decrease in viscosity with temperature, which at $55^{\circ} \mathrm{C}$ is about $12 \mathrm{cP}$ for the $23: 77$ mixture and therefore, at a viscosity range where lifetime becomes again dependent on viscosity. In other words, at the beginning of the experiment, when the viscosity is high $\left(50 \mathrm{cP}\right.$ at $\left.25{ }^{\circ} \mathrm{C}\right)$ the lifetime is independent of viscosity, however when the temperature increases, the viscosity changes to a point where the lifetime again becomes viscosity dependent. At mixtures with higher percentage of glycerol $\left(>100 \mathrm{cP}\right.$ at $\left.25^{\circ} \mathrm{C}\right)$, the viscosity is high enough (even at high temperatures) that the lifetime remains virtually independent of viscosity throughout most of the experiment with some small deviations observable at $55{ }^{\circ} \mathrm{C}$. (b) The same data is presented as lifetime vs viscosity and it is evident that after a certain viscosity the lifetime for a given temperature is unchanged. 
Table S1. PI/Annexin V FACS assay of PEG-BODIPY in HPNE cells at 24 and $48 \mathrm{~h}$.

\begin{tabular}{l|llllllllll}
\multicolumn{3}{c}{ PEGBODIPY } & \multicolumn{2}{c}{ Early apop. } & \multicolumn{2}{c}{ Late apop. } & \multicolumn{2}{c}{ Live } & \multicolumn{3}{c}{ Necrotic } \\
\hline & $24 \mathrm{~h}$ & $48 \mathrm{~h}$ & $24 \mathrm{~h}$ & $48 \mathrm{~h}$ & $24 \mathrm{~h}$ & $48 \mathrm{~h}$ & $24 \mathrm{~h}$ & $48 \mathrm{~h}$ & $24 \mathrm{~h}$ & $48 \mathrm{~h}$ \\
$0 \mu M$ & 0.0 & 0.0 & 1.1 & 1.4 & 0.5 & 0.5 & 96.1 & 93.1 & 2.3 & 4.9 \\
$10 \mu M$ & 0.3 & 0.2 & 1.9 & 1.3 & 0.3 & 0.6 & 97.1 & 96.2 & 0.7 & 1.9 \\
$50 \mu M$ & 58.4 & 71.7 & 3.0 & 1.5 & 0.7 & 0.8 & 92.3 & 95.8 & 4.0 & 1.9 \\
$100 \mu M$ & 99.7 & 99.7 & 2.2 & 1.0 & 0.5 & 1.0 & 94.1 & 94.4 & 3.2 & 3.7 \\
$200 \mu M$ & 100.0 & 100.0 & 1.3 & 0.9 & 0.7 & 1.2 & 95.2 & 94.9 & 2.9 & 3.0 \\
$300 \mu M$ & 100.0 & 100.0 & 1.1 & 1.4 & 1.2 & 1.6 & 96.1 & 94.6 & 1.6 & 2.5 \\
$500 \mu M$ & 100.0 & 100.0 & 1.0 & 2.5 & 1.2 & 2.5 & 95.3 & 90.3 & 2.5 & 4.7 \\
heat & 0.0 & 0.0 & 4.4 & 5.7 & 89.3 & 90.0 & 1.7 & 2.4 & 4.6 & 1.8 \\
shock & & & & & & & & & &
\end{tabular}
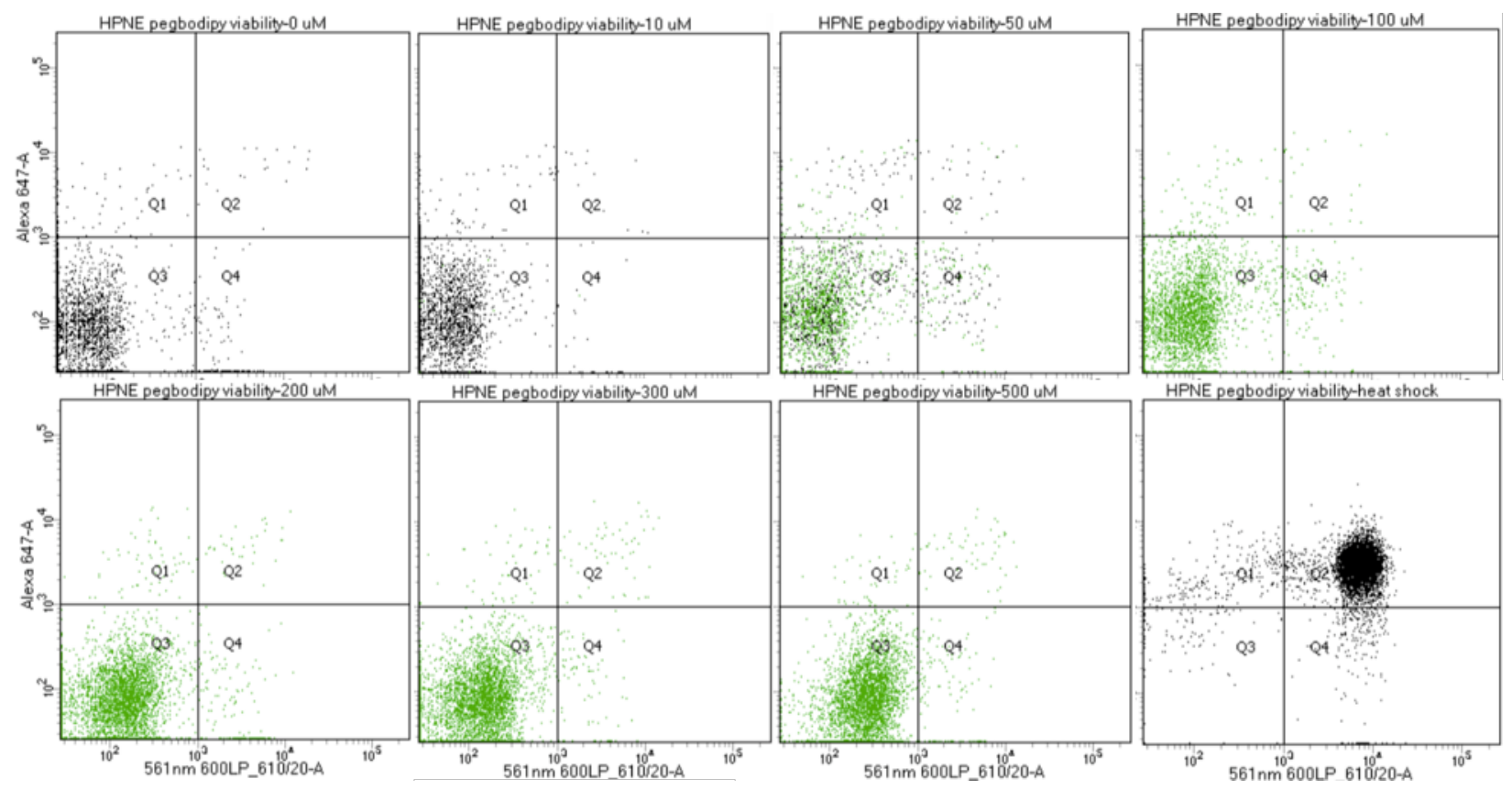

Figure S5. HPNE flow cytometry. Cells stained with PEG-BODIPY are marked in green. X-axis shows propidium iodide fluorescence and y-axis shows annexin V/AF647 fluorescence. 
Table S2. PI/Annexin V FACS assay of PEG-BODIPY in Panc-1 cells at 24 and $48 \mathrm{~h}$.

\begin{tabular}{l|llllllllll}
\multicolumn{1}{c}{ PEGBODIPY } & \multicolumn{2}{c}{ Early apop. } & \multicolumn{2}{l}{ Late apop. } & \multicolumn{2}{c}{ Live } & \multicolumn{3}{c}{ Necrotic } \\
\hline & $24 \mathrm{~h}$ & $48 \mathrm{~h}$ & $24 \mathrm{~h}$ & $48 \mathrm{~h}$ & $24 \mathrm{~h}$ & $48 \mathrm{~h}$ & $24 \mathrm{~h}$ & $48 \mathrm{~h}$ & $24 \mathrm{~h}$ & $48 \mathrm{~h}$ \\
$0 \mu M$ & 0.0 & 0.0 & 1.7 & 2.8 & 1.0 & 1.3 & 96.8 & 95.2 & 0.5 & 0.6 \\
$10 \mu M$ & 0.2 & 0.1 & 2.1 & 2.8 & 1.0 & 1.2 & 96.1 & 95.4 & 0.8 & 0.6 \\
$50 \mu M$ & 53.4 & 15.7 & 2.5 & 6.7 & 1.2 & 1.5 & 95.1 & 91.4 & 1.2 & 0.5 \\
$100 \mu M$ & 98.9 & 78.9 & 3.0 & 5.2 & 1.5 & 1.5 & 94.8 & 92.4 & 0.7 & 0.9 \\
$200 \mu M$ & 99.7 & 97.9 & 4.2 & 10.2 & 1.7 & 3.3 & 93.2 & 84.4 & 0.8 & 2.1 \\
$300 \mu M$ & 99.7 & 99.0 & 8.0 & 21.4 & 2.4 & 2.7 & 88.7 & 75.7 & 0.9 & 0.1 \\
$500 \mu M$ & 99.9 & 99.4 & 11.5 & 4.9 & 4.2 & 7.4 & 83.4 & 46.1 & 0.9 & 0.7 \\
heat & 0.7 & 0.0 & 2.3 & 3.6 & 85.1 & 36.1 & 1.1 & 6.6 & 11.5 & 53.8 \\
shock & & & & & & & & & &
\end{tabular}
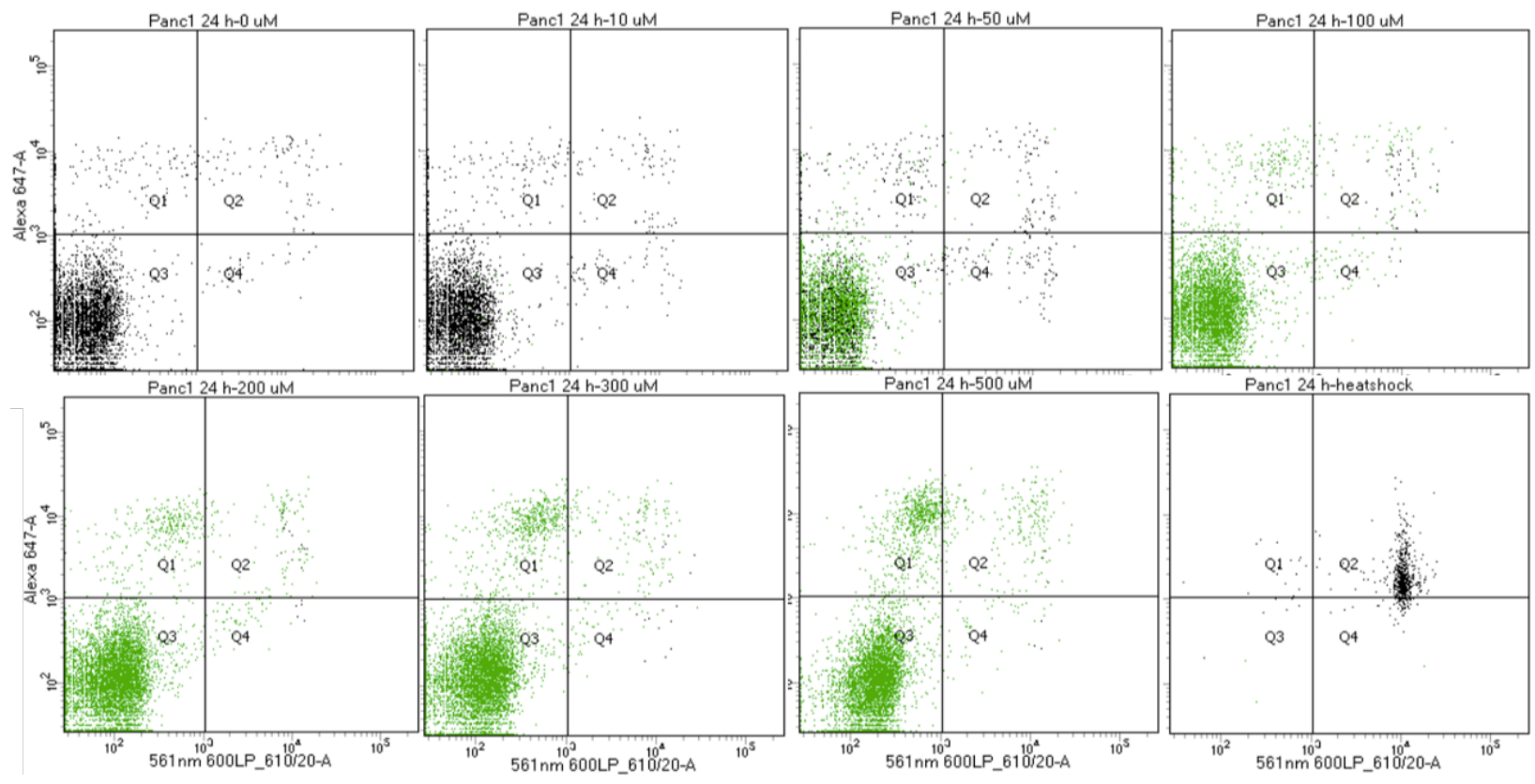

Figure S6. Panc-1 flow cytometry. Cells stained with PEG-BODIPY are marked in green. X-axis shows propidium iodide fluorescence and y-axis shows annexin V/AF647 fluorescence. 


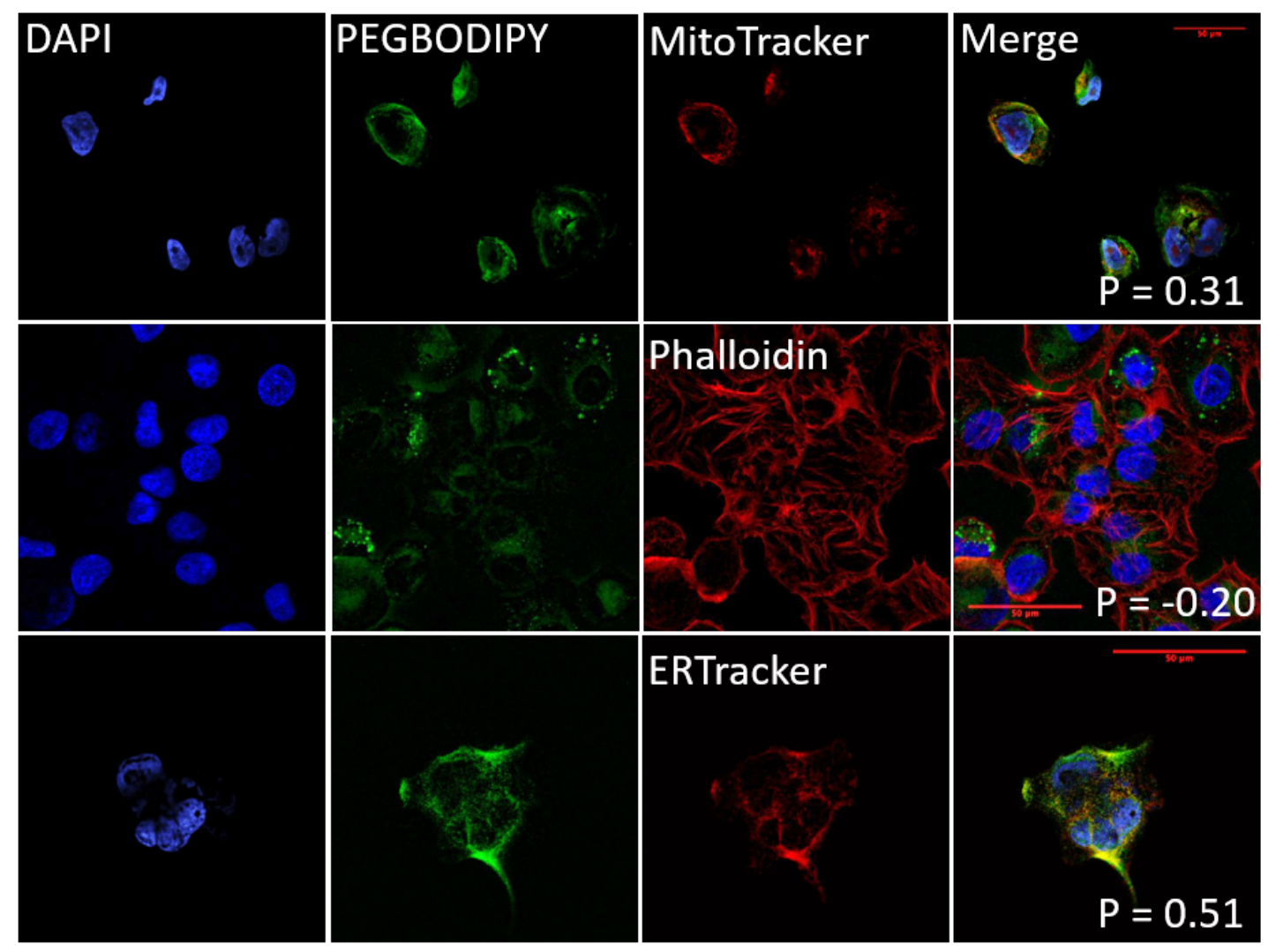

Figure S7. Colocalization of PEG-BODIPY with different cellular stains in Panc-1 cells. (Scale bar 50 $\mu \mathrm{m})$

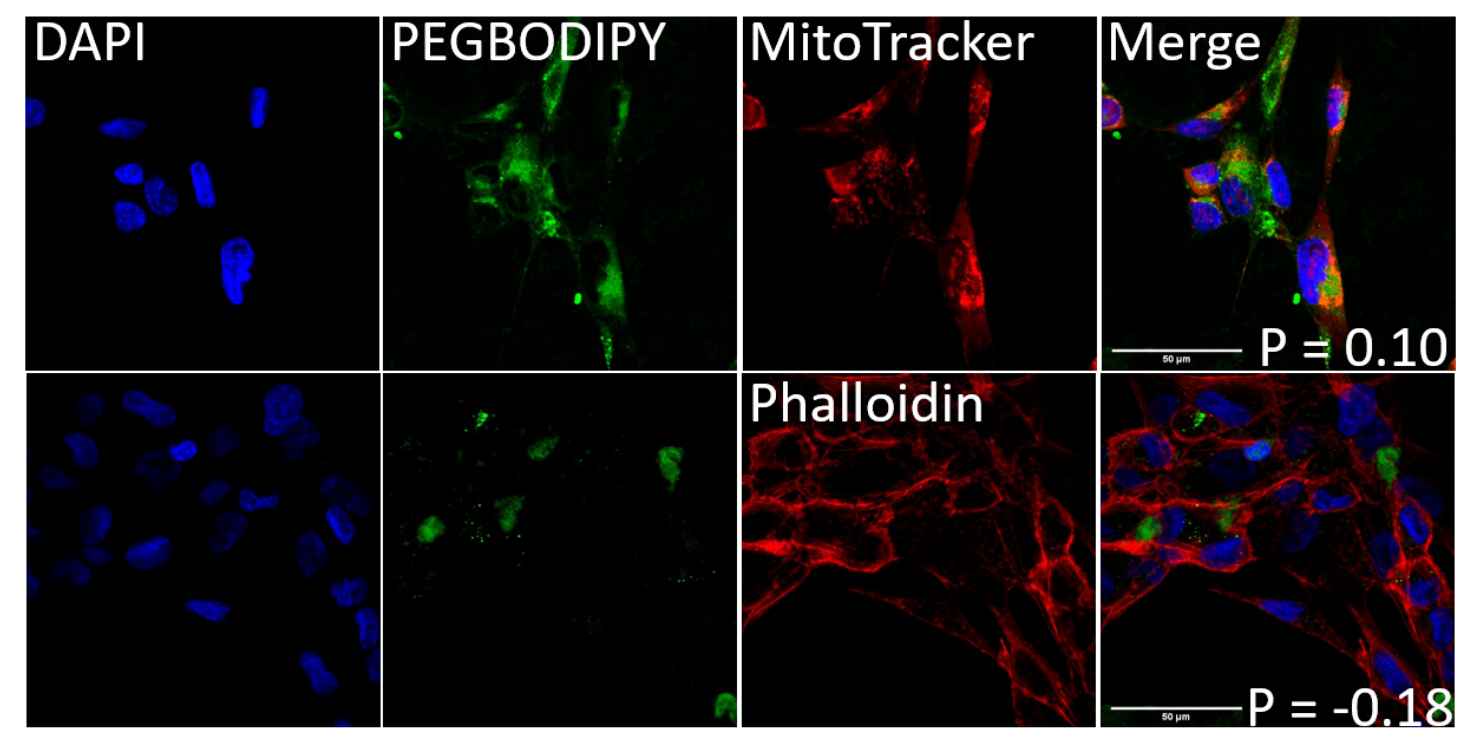

Figure S8. Colocalization of PEG-BODIPY with different cellular stains in HPNE cells. (Scale bar 50 $\mu \mathrm{m})$. 


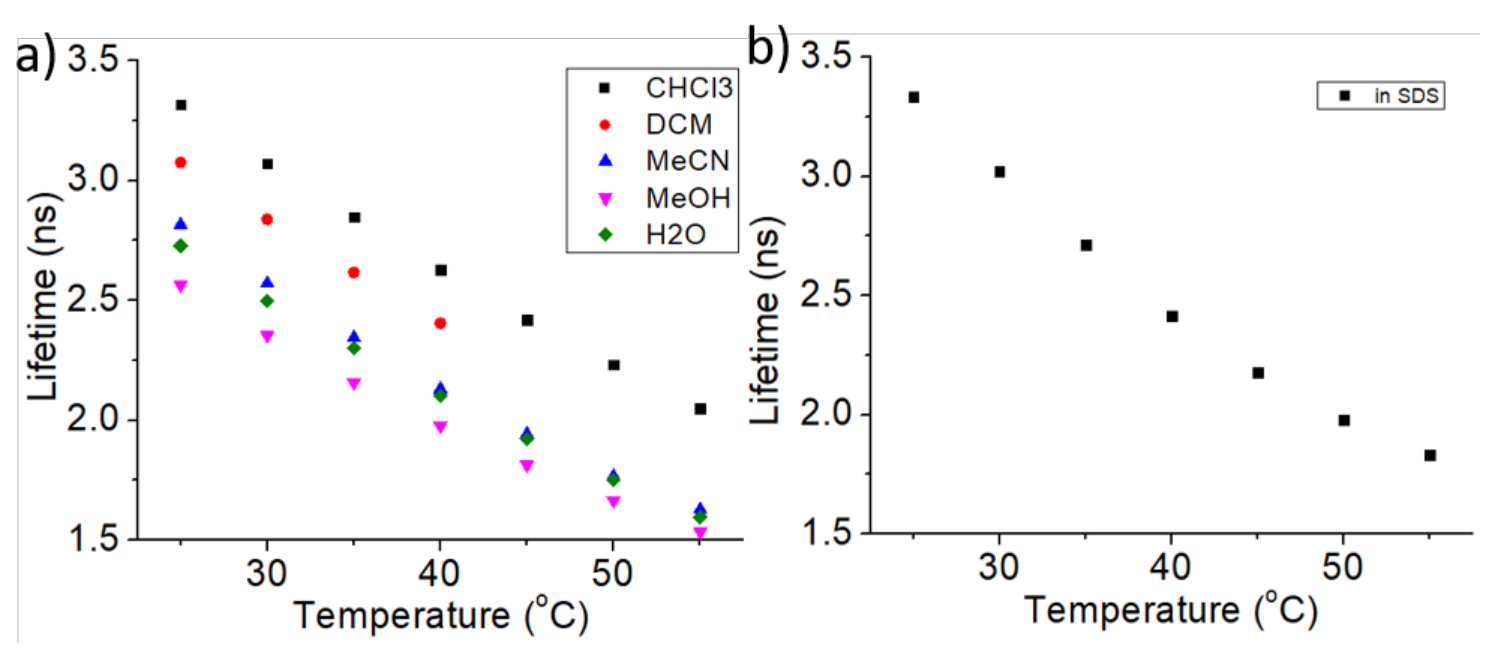

Figure S9. (a) Lifetime of PEG-BODIPY $(20 \mu \mathrm{M})$ in different polarity solvents. The data shows that, although the trend with temperature is the same, as polarity increases lifetime decreases. (b) Lifetime of PEG-BODIPY $(20 \mu \mathrm{M})$ in aqueous SDS $(8.5 \mathrm{mM})$ vs temperature. The lifetime is increased in the hydrophobic micelles of SDS compared to water.
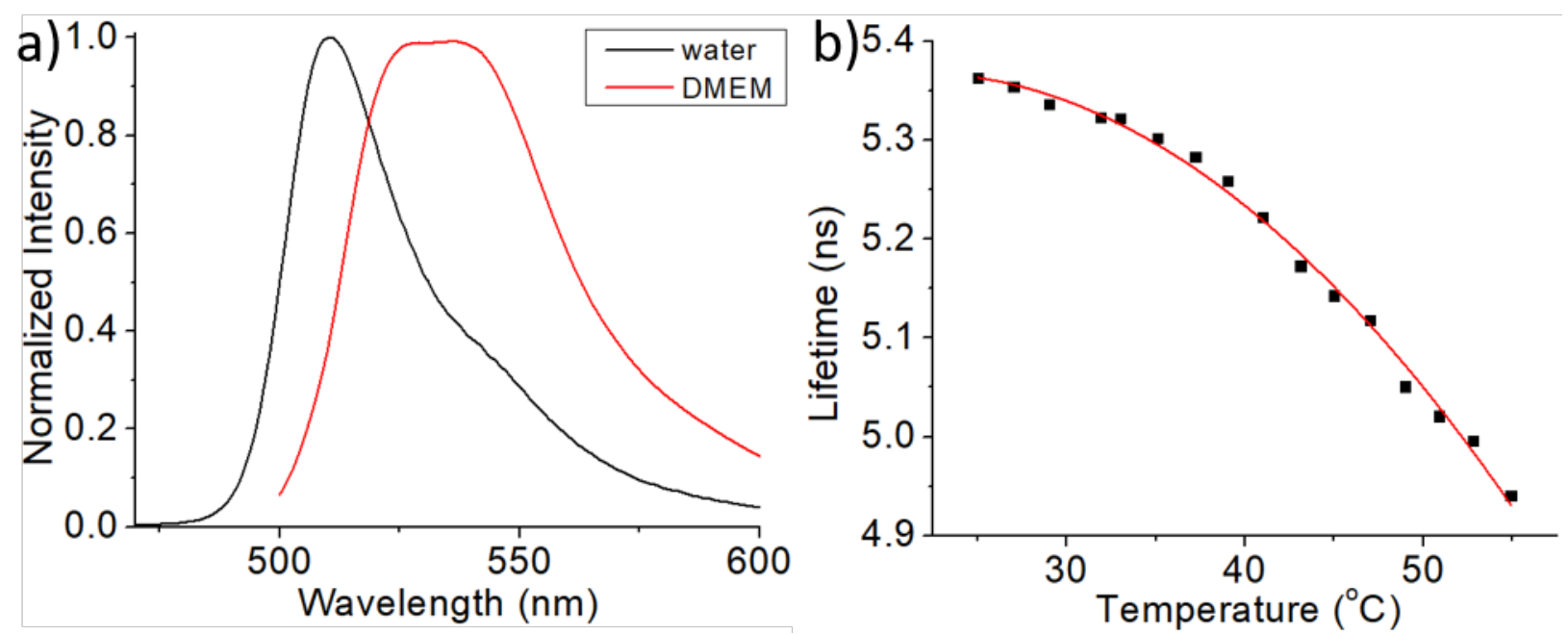

Figure S10. (a) Emission spectra of PEG-BODIPY in water and DMEM growth media ( $\left.\lambda_{\text {ex }} 444 \mathrm{~nm}\right)$. (b) Lifetime $\left(\tau_{2}\right)$ vs temperature of PEG-BODIPY in DMEM. Curve fit: $\mathrm{y}=5.19+0.017 \mathrm{~T}-0.00039 \mathrm{~T}^{2}$. $\mathrm{R}^{2}$ $=0.994$. 
Table S3. Fitting parameters for data shown in Fig S10b. $y=A_{1} e^{-t / \tau_{1}}+A_{2} e^{-t / \tau_{2}}+y_{0}$

\begin{tabular}{l|llllll}
$\begin{array}{l}\text { Temp. } \\
\left({ }^{\circ} \mathrm{C}\right)\end{array}$ & $\tau_{1}(n s)$ & $\%$ & $\tau_{2}(n s)$ & $\%$ & $\tau_{\text {avg }}$ & $\chi^{2}$ \\
\hline 25.0 & 1.56 & 17 & 5.36 & 83 & 4.70 & 1.17 \\
27.0 & 1.48 & 18 & 5.35 & 82 & 4.66 & 1.10 \\
29.0 & 1.39 & 19 & 5.34 & 81 & 4.58 & 1.36 \\
31.9 & 1.29 & 19 & 5.32 & 81 & 4.55 & 1.09 \\
33.0 & 1.35 & 21 & 5.32 & 79 & 4.50 & 1.27 \\
35.1 & 1.31 & 21 & 5.30 & 79 & 4.48 & 1.11 \\
37.2 & 1.29 & 21 & 5.28 & 79 & 4.43 & 1.10 \\
39.0 & 1.33 & 23 & 5.26 & 78 & 4.40 & 1.17 \\
41.0 & 1.30 & 24 & 5.22 & 76 & 4.27 & 1.26 \\
43.1 & 1.29 & 25 & 5.17 & 75 & 4.21 & 1.12 \\
45.0 & 1.27 & 26 & 5.14 & 74 & 4.15 & 1.07 \\
47.0 & 1.28 & 27 & 5.12 & 73 & 4.07 & 1.00 \\
49.0 & 1.25 & 28 & 5.05 & 72 & 3.98 & 1.02 \\
50.9 & 1.22 & 29 & 5.02 & 71 & 3.92 & 1.08 \\
52.8 & 1.21 & 30 & 5.00 & 70 & 3.86 & 1.11 \\
54.9 & 1.19 & 31 & 4.94 & 69 & 3.77 & 0.96 \\
& & & & & &
\end{tabular}




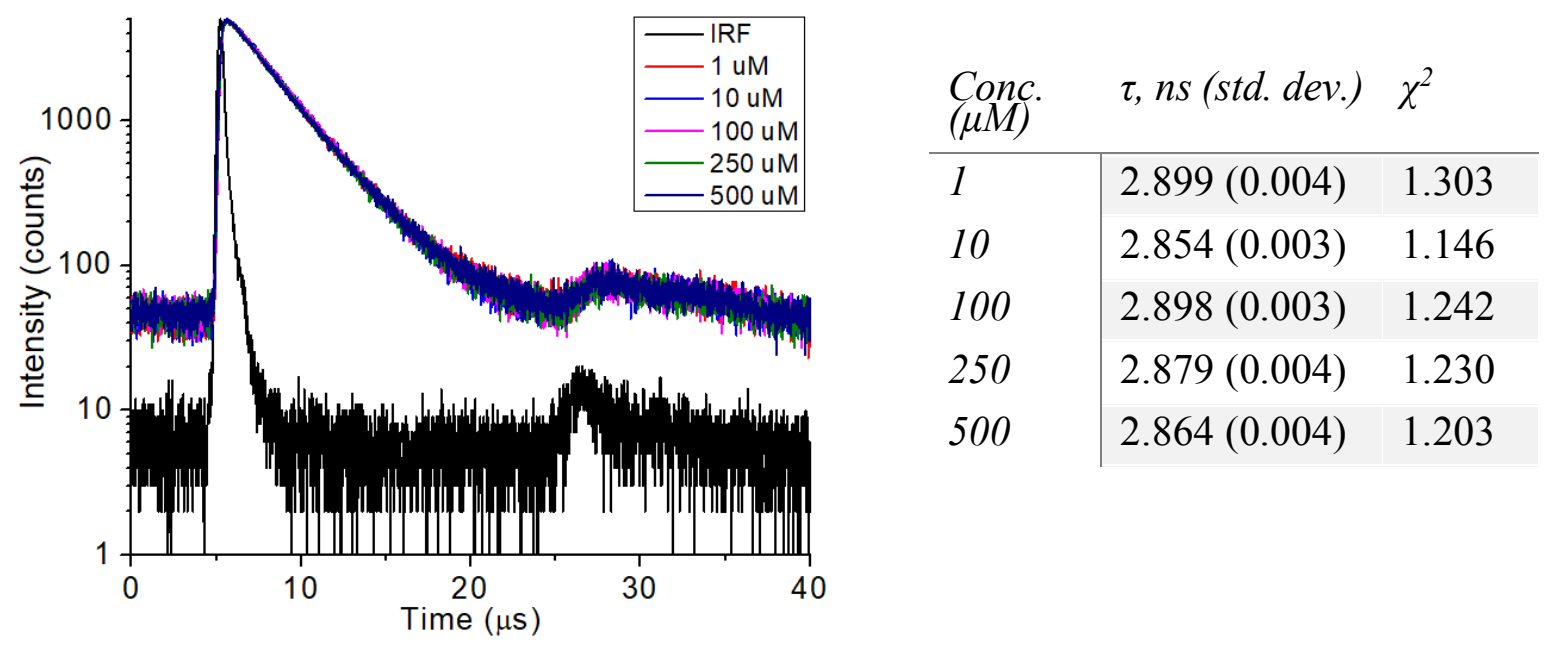

Figure S11. Lifetime of PEG-BODIPY at different concentrations. Lifetime is not changed at high concentrations and remains monoexponential. This implies that aggregation does not happen as the concentration is increased.

Table S4. Fitting parameters for HPNE FLIM data shown in Fig 7. $y=A_{1} e^{-t / \tau_{1}}+A_{2} e^{-t / \tau_{2}}+y_{0}$

\begin{tabular}{l|llllll}
$\begin{array}{l}\text { Temp. } \\
\left({ }^{\circ} \mathrm{C}\right)\end{array}$ & $\begin{array}{l}\tau_{1}, n s \\
(\text { std. dev. })\end{array}$ & $\%$ & $\begin{array}{l}\tau_{2}, n s \\
(\text { std. dev. })\end{array}$ & $\%$ & $\tau_{\text {avg }, n s}$ & $\chi^{2}$ \\
\hline 25 & $\begin{array}{l}5.202 \\
(0.008)\end{array}$ & 81 & $\begin{array}{l}1.96 \\
(0.01)\end{array}$ & 19 & 4.59 & 1.190 \\
30 & $\begin{array}{l}5.134 \\
(0.008)\end{array}$ & 79 & $\begin{array}{l}1.94 \\
(0.01)\end{array}$ & 21 & 4.46 & 1.036 \\
35 & $\begin{array}{l}5.055 \\
(0.008)\end{array}$ & 78 & $\begin{array}{l}1.90 \\
(0.01)\end{array}$ & 22 & 4.36 & 1.160 \\
40 & $\begin{array}{l}4.935 \\
(0.007)\end{array}$ & 77 & $\begin{array}{l}1.82 \\
(0.01)\end{array}$ & 23 & 4.22 & 1.116 \\
45 & $\begin{array}{l}4.817 \\
(0.007)\end{array}$ & 75 & $\begin{array}{l}1.77 \\
(0.01)\end{array}$ & 25 & 4.06 & 1.112 \\
50 & $\begin{array}{l}1.660 \\
(0.006)\end{array}$ & 73 & $\begin{array}{l}1.686 \\
(0.008)\end{array}$ & 27 & 3.857 & 1.207 \\
55 & $\begin{array}{l}4.498 \\
(0.005)\end{array}$ & 69 & $\begin{array}{l}1.579 \\
(0.006)\end{array}$ & 31 & 3.593 & 1.303
\end{tabular}



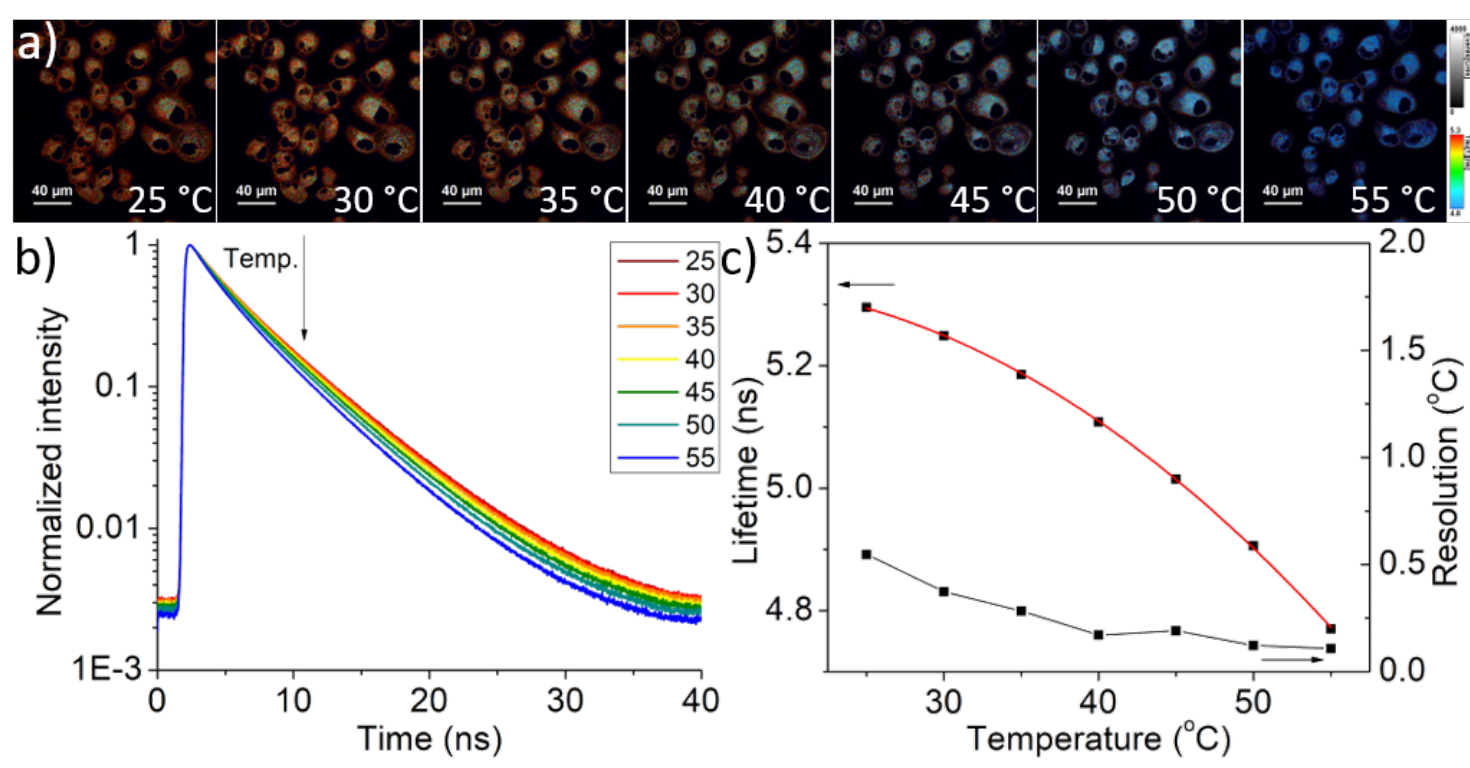

Figure S12. Panc-1 FLIM studies. (a) FLIM images of Panc-1 cells false colored with scale 4.2 ns (blue) to $5.2 \mathrm{~ns}$ (red). (b) Lifetime decays of the long component $\left(\tau_{1}\right)$. (c) Quadratic fit of lifetime vs. temperature of $\tau_{1} 25-55^{\circ} \mathrm{C} . \tau=5.26+0.0097 \mathrm{~T}-0.00034 \mathrm{~T}^{2} . \mathrm{R}^{2}=0.999$.

Table S5. Fitting parameters for Panc-1 FLIM data. $y=A_{1} e^{-t / \tau_{1}}+A_{2} e^{-t / \tau_{2}}+y_{0}$

\begin{tabular}{|c|c|c|c|c|c|c|}
\hline $\begin{array}{l}\text { Temp. } \\
\left({ }^{\circ} \mathrm{C}\right)\end{array}$ & $\begin{array}{l}\tau_{1}, n s \\
\text { (std. dev.) }\end{array}$ & $\%$ & $\begin{array}{l}\tau_{2}, n s \\
\text { (std. dev.) }\end{array}$ & $\%$ & $\tau_{a v g}, n s$ & $\chi^{2}$ \\
\hline 25 & $\begin{array}{l}5.295 \\
(0.004)\end{array}$ & 84 & $\begin{array}{l}1.939 \\
(0.006)\end{array}$ & 16 & 4.758 & 1.661 \\
\hline 30 & $\begin{array}{l}5.249 \\
(0.004)\end{array}$ & 84 & $\begin{array}{l}1.935 \\
(0.007)\end{array}$ & 16 & 4.719 & 1.520 \\
\hline 35 & $\begin{array}{l}5.186 \\
(0.004)\end{array}$ & 84 & $\begin{array}{l}1.922 \\
(0.006)\end{array}$ & 16 & 4.664 & 1.576 \\
\hline 40 & $\begin{array}{l}5.108 \\
(0.003)\end{array}$ & 83 & $\begin{array}{l}1.902 \\
(0.006)\end{array}$ & 17 & 4.563 & 1.726 \\
\hline 45 & $\begin{array}{l}5.015 \\
(0.004)\end{array}$ & 82 & $\begin{array}{l}1.878 \\
(0.006)\end{array}$ & 18 & 4.450 & 1.585 \\
\hline 50 & $\begin{array}{l}4.906 \\
(0.003)\end{array}$ & 81 & $\begin{array}{l}1.836 \\
(0.005)\end{array}$ & 19 & 4.323 & 1.635 \\
\hline 55 & $\begin{array}{l}4.770 \\
(0.003)\end{array}$ & 79 & $\begin{array}{l}1.761 \\
(0.005)\end{array}$ & 21 & 4.138 & 1.624 \\
\hline
\end{tabular}

